\title{
S38. Long-term studies in psychiatry
}

PREMORBID ADJUSTMENT AS PREDICTOR OF OUTCOME IN BCHIZOPHRENIA: RESULTS OF A 3-YEAR FOLLOW-UP STUDY

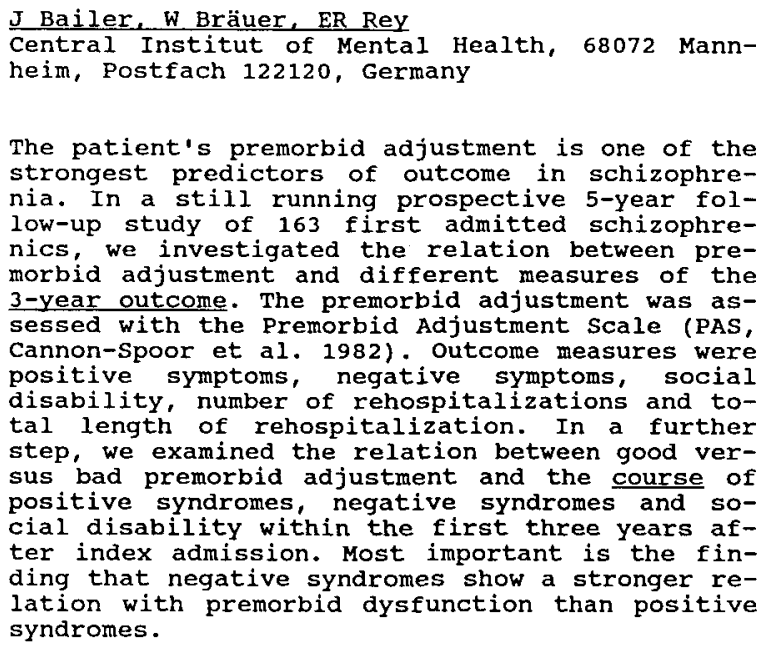
sus bad premorbid adjustment and the course of positive syndromes, negative syndromes and social disability within the first three years after index admission. Most important is the finding that negative syndromes show a stronger relation with premorbid dysfunction than positive syndromes.

\author{
LONGITUDINAL COURSE OF SUBTYPES IN SCHIZOPHRENIF \\ IN COMPARISON OF FOUR DIAGNOSTIC SYSTEMS \\ A Deister \\ Psychiatric University Hospital, University of Bonn \\ Sigmund-Freud-Str. 25, D-53105 Bonn
}

The subclassification of schizophrenic disorders according to fou diagnostic systems (DSM-III-R, ICD-10, the positive vs. negative dichotomy and Schneider's first rank symptoms) was comparer over the long-term course of the disease in 148 narrowly defines schizophrenic patients. A total of 595 episodes were classifie over a mean observation period of 23 years (range $10-50$ years).

Initially, paranoid/positive subtypes predominated, while later in the course episodes fullfilling the symptomatological criteria o residual/negative subtypes became more frequent. Long-term stabi lity was not the rule but the exception. The frequency of stable course (i.e. all episodes having the same subtype) was found to br depend on the type of the initial episode. In most cases a subtype change occurred within the first few years of the illness with $n$ clear direction. The findings were similar for DSM-III-R, ICD-10 ane positive negative dichotomy. Only in patients beginning withou first-rank symptoms were more stable than non-stable course: found.

The results of this study do not support the assumption that stable subtypes are nosological or etiopathogenetic subentities of schizo phrenic disorders. 
GENDER AND NEED FOR CARE IN CHRONIC SCHIZOPHRENIA RKR Salokangas

Department of Psychiatry, University of Turku, 20520 Turku, Finland

Since the beginning of 1980s, beds in mental hospitals have decreased very quickly in Finland. When the number of psychiatric beds in 1980 was nearly 4 per 1000 people, ten years later the corresponding figure was about a half of it. During the same time period, there have been only very small increase in psychiatric outpatient facilities raising a question, how the patients discharged from hospitals have found their place in community and what is their treatment situation at the time of diminishing psychiatric services. These questions were studied by a national sample of Discharged Schizophrenic Patients (DSP study).

The DSP sample consisted of 1097 15-64 year-old patients who suffered from schizophrenic disorder (DSM III R) and who in 1986 were discharged from mental hospitals in 19 Health Care Districts in Finland. Patients were followed for three years. More men than women were discharged: a prevalence figure of patients discharged in a month was 0.18 per 1000 people for males and 0.14 for females. At the follow-up, 20 \% of patients were hospitalized, $7 \%$ in other residential care, $7 \%$ in day care, 45 \& had a contact to Mental Health Centre and 21 \% was out of psychiatric care. When primary health care and social services were taken account, $10 \%$ was totally out of care. Need for non-hospital residential and day care was twice as high as the use of these services. Accordingly, the need for various rehabilitating measures was clearly higher than what the psychiatric care system could produce. Functional outcome was poorer and need for rehabilitation greater for males than females. Results are discussed in light of gender differences in outcome and need for and use of psychiatric care.

\section{COURSE AND OUTCOME OF DELUSIONAL BELIEFS}

\section{P jorgensen}

Psychiatric Hospital in Aarhus, Dept. A, Skovagervej 2, DK-8240 Risskov, Denmark.

A group of 88 delusional patients has been followed prospectively from first admission. The 2-, 4-, and 8-years course and outcome for 75 patients still alive are presented according to main delusional theme at index admission and from a dimensional approach. From the time of index admission, the groups of patients differed with respect to preceding course and global functioning. In general, these differences were maintained although some became more pronounced. The most optimistic perspective appears for patients with main delusion of reference or a low dimensional severity of delusional beliefs and the most pessimistic for patients with main delusions of persecution or influence and for those with a high dimensional severity of delusional beliefs. Thirty two patients remained delusional throughout the observation period, in most cases with unchanged thematical contens; $57 \%$ had an episodic and 43\% a chronic course.

After 8 years of observation, the diagnostic distribution is presented according to the ICD-10 and the DSM-III-R classification systems among which a large degree of agreement was found. Schizophrenia turned out to be the most frequent diagnosis but almost half of the patients belonged to another diagnostic category. Global assessment functoning (GAF) at 8-year follow-up is: schizophrenia, 35; affective disorder, 82; persistent delusional disorder, 50; and acute and transient psychotic disorder, 72.

During the observation period five patients commited suicide which means that delusional first-admitters have a risk of suicide which is 31,5 times higher than the general population's.

In the presence of all independent predictors, the persistence of delusional beliefs is predicted for $94 \%$ of the present patient population.
PROGNOSIS AND LONG-TERM COURSE IN POSTPARTUM PSYCHOSES; A FOLLOW-UP STUDY (1967 - 1989).

JL Klompenhouwer, WJ Schudel, PGH Mulder

Vincent van Gogh Institute for Psychiatry, Dept. Biological Psychiatry, P.O. Box 5, 5800 AA Venray, The Netherlands

In a follow-up study varying from $2-22$ years it was established that the case fatality rate in the group of patients admitted to the Rotterdam mother and baby unit was $1,3 \%$. The suicide rate in the aftermath of postpartum mental disorder was 1,13 per thousand person years. This risk is approximately 20 fold increased compared to the risk for the population at large. Overall, prognosis for postpartum mental disorder is favorable. This is illustrated by the fact that after an average follow-up of 11 years $97,5 \%$ of the patients are still living in the community and $2,5 \%$ of the patients are living in mental hospitals. However these results do not imply that patients with postpartum psychiatric disorder will never be confronted with mental illness again. We established that after an average follow-up of 10,3 years the majority of the patients $(57 \%)$ will, at least once, have called in the help of a General Practitioner or Mental Health Institution because of psychiatric problems (rate per thousand person years $=56$ ). In a large majority of these patients the recurrences of mental illness were nonpuerperal. The mental health problems occurring in the aftermath of the index illness were serious to such a degree that an episode of hospitalization was considered necessary in $40 \%$ of the patients (Rate/1000 p.y. $=39,3$ ). The massive impact of childbirth on the mental health of these women is illustrated by a recurrence risk of $41 \%$ after subsequent pregnancy and delivery. Strong predictors of the longterm outcome are the presence or absence of psychiatric illness prior to the puerperal episode and the duration of hospitalization because of the index illness. The predictive value of the RDC classification is limited.

EVALUATION AND FOLLOW-UP IN 100 PATIENTS IMMEDIATELY AFTER A VIOLENT SUICIDE ATTEMPT.

CSF 5-HIAA AND PERIPHERAL 5-HT PARAMETERS IN A SUBGROUP .

D. Cremniter $^{1}$, S. Jamain 1 , K. Kollenbach ${ }^{2}$, O. SpreuxVaroquaux $^{2}$, A. Meidinger ${ }^{1}$, F. Bonnet ${ }^{1}$, I. Macquin-Mavier ${ }^{1}$, B. Larget-Piet ${ }^{1}, M$. Thénault ${ }^{1}$.

1-Hôpital Henri Mondor 94000 Creteil - France

2 _ Centre Hospitalier de Versailles 78157 - France

100 patients seen in different surgical or medical intensive care units of a general hospital were included. The most frequent methods, were severe overdoses(24\%) defenestration (24\%), and fire arms(17\%). Each patient was seen by a psychiatrist who carried out an interview in order to establish the diagnosis according to DSM III $R$ criteria. The most frequent underlying psychiatric disorders were major depression (40\%), psychoses (28\%). The follow up at 6 months and at one year was conducted by recontacting the patients. The frequency of the recurrence of suicidal acts at 6 months was $4.3 \%$.

CSF levels of 5-HIAA, plasma free 5-HT levels and platelets 5-HT concentrations were determined in 15 patients up to 5 days after the attempt. Most of them were untreated $(n=13)$. These values have been compared to the same parameters measured in a control population $(n=12)$ who underwent lumbar puncture for rhumatologic disease. CSF 5-HIAA levels in the suicide group were significantly higher than in controls $(p=0.03$, MannWhitney U-test). These results are different from those found in most similar studies. There were no differences in plasma free 5-HT levels or platelet 5-HT content between patients and controls. 
THE GALWAY STUDY OF PANIC DISORDER III: SIX YEAR FOLLOW-UP O'Rourke, D. Brophy, J., Fahy, T.J.

Dept. of Psychiatry, University College Hospital, Galway, Ireland

Of 79 graduates of a controlled drug trial of DSM III R Panic Disorder with and without Agoraphobia 68 were assessed 6 years later. $33 \%$ had remitted and had remained well, the remainder having a smouldering course. A minority did badly. Initial severity and chronicity predicted poor outcome as did a family history of PD and inability to recall the first attack. An initial clinical judgement of personality impairment also predicted poor long term outcome. Diagnosis (of PD) was remarkably stable over time. Mode of treatment, choice of drug, use of services and retrospective attributional benefit by the patients did not predict long term outcome. These data point to a minority group of poor prognosis with special treatment needs.
THE NORWEGIAN FOLLOW-UP STUDY OF THE TREATMENT OF PATIENTS WITH TRANSSEXUALISM

AA Dah1, B Grünfeld, CA Guldberg, H Hansen, E Kjelsberg

Since 196365 patients with transsexualism according to DSM-III-R criteria have been treated with sex reassignnent surgery in Norway. 63 of these patients were located within Scandinavia, and all these patients had a personal follow-up examination by a psychiatrist. We therefore only missed two patients which had moved outside Scandinavia.

The sample had been selected according to the criteria of Wålinder \& Lundström for surgical treatment. 23 were converted to men and 40 to women. Mean follow-up time was 8.1 years with a range of 1 to 26 years. The mean age at operation was 28.6 years with a range of 19 to 52 years.

The patients were examined by SCL-90, GHQ, and TPQ as selfreport instruments. They were interviewed with SCID axis I and II for DSM-III-R diagnoses. In addition they had a life history interview as to transsexualism. The outcome of the sex reassignment surgery was measured with thunt \& Hampsons multidimensional outcome scale.

45 of the 63 patients had a very good outcome according to Hunt \& Hampsons scale. One patients had comitted suicide and one had schizophrenia. On DSM-III-R axis one 13 patients have had major depression and 14 an anxiety disorder, while other disorders were rare. On axis II 7 patients had an avoidant, 8 a paranoid, and 6 patients an antisocial personality disorder.

This is the first outcome study of patients with transsexualism using structured interviews and DSM-III-R diagnoses. The whole sample has been followed up, and the results are very good on most dimensions. The differences in outcone between men and women are not significant.

Department of Psychiatry, University of Oslo and National Hospital, University of Oslo

P.0. Box 33, Gaustad, 0320 Oslo, Norway 